Drayer Turner et al. HCA Healthcare Journal of Medicine (2020) 1:COVID-19

https://doi.org/10.36518/2689-0216.1118

\title{
Narrative Medicine
}

\section{COVID Intensive Care Unit Through the Eyes of Ophthalmologists}

Laura Drayer Turner, MBBS, MA (Oxon), PGCert (MedEd),' Dharshana Ramanathan, BSc (Hons), MBBS,' Sneha Melmane, MBBS, Dip Ophthalmology, DNB Ophthalmology, Geeta Menon, FRCS, FRCOphth, FRCP (Lond)'

\section{Abstract}

\section{Description}

The disproportionate impact of COVID on the mortality and morbidity of people of black, Asian and minority ethnic (BAME) backgrounds has been recognised and is under investigation. Here we present a different impact: that on the psyche. As three doctors of BAME heritage, we shared an experience of being redeployed from ophthalmology to the COVID Intensive Care Unit. We share our reflections on the experience and lessons learned.

Author affiliations are listed at the end of this article.

Correspondence to:

Laura Drayer Turner

Frimley Park Hospital NHS

Trust

Portsmouth Road

Frimley, UK

GU16 7UJ

(ldrayerturner@nhs.net)

\section{Keywords}

SARS-CoV-2; COVID-19; pandemics; coronavirus infections; intensive care units; disease outbreaks/prevention \& control; patient care team; minority health

In this paper, we, as three ophthalmologists of Black Asian and Minority Ethnic (BAME) backgrounds, reflect on our journey looking after critically unwell patients with COVID in the Intensive Care Unit (ICU). With the ongoing investigations into the impact of this virus on BAME communities, we feel lucky to have come out the other end of this redeployment experience physically, although not emotionally, unscathed. We realise now that our professional work, studies and experiences over the last few years have been largely myopic and have found this experience truly eye opening, no pun intended.

The gravity of the situation became clear as the number of deaths began to increase across Europe. The National Health Service (NHS) was on a war footing and we were hearing news about how our hospitals would be overwhelmed during the crisis. Immediate changes began to evolve in the eye department such as the creation of slit lamp shields, social distancing in waiting rooms and the cancellation of elective surgeries, amongst many more.
Despite news of doctors in central London hospitals being deployed to the wards, we were still in a state of denial that our hospital could ever reach such a stage. Having chosen to train as ophthalmologists, to step out of what had become our cocoon over the past few years and to join a new workforce seemed surreal.

There was a growing realisation that outside our little haven in ophthalmology, an imminent battle lay ahead, and it was important for us to unite to see it through. A flurry of training resources swamped our inboxes, from induction dates to refresher webinars, once it was confirmed that we were being deployed to look after COVID positive patients in the ICU. AIthough concerns had already been raised about BAME communities possibly being at increased risk for adverse outcomes with the virus, we did not even think twice about being deployed due to our backgrounds.

Suddenly there were lots of questions. What will be expected of us? Will we have senior supervision? Should we move out of our family homes? Were we putting our families at too www.hcahealthcarejournal.com

(C) 2020 HCA Physician Services, Inc. d/b/a Emerald Medical Education
HCA Healthcare Journal of Medicine 
much risk? There were a whole host of unknowns, and there was a heightened sense of uncertainty each day. What we did know was that this experience would stay with us forever. Alongside doctors from numerous specialities, we joined the welcoming team of intensivists and anaesthetists. Each shift began with a handover, with detailed updates of our patients and plans to manage the different ICU areas. Prior to entering the COVID area, we would help each other to make sure we had donned our PPE properly.

The ICU was constantly over capacity, so even our little help went a long way. We were each in charge of two or three patients, and we would discuss their care in great detail with the consultants and plan the management for the day during ward rounds. Many of our patients were from the BAME community, and we could not help but draw parallels to our own family and friends. Our tasks were relatively small-'proning' patients, ordering investigations, monitoring and updating the records-with important decisions being left to the intensivists. The consultants constantly encouraged everyone to take regular breaks while they tirelessly monitored patients. Amidst the constant ward rounds and the over capacity of patients, they would always make time to teach us.

Treating patients in the ICU was challenging enough, but communicating with their relatives waiting anxiously at home was extremely difficult. It was heart-breaking that they were not able to see or even speak to their ill family member. Our calls to update relatives on their loved ones were received with eagerness and made a big difference to them and us, even if it was usually not good news.

Throughout our professional careers, we are taught how important it is to communicate with our patients. However, when patients are on ventilators with tubes down their throats and, at times, unconscious, it was exceedingly difficult to do so. Even though our masks obscured most of our face, we hoped they were able to see our reassuring smiles lighting up our eyes. A small thumbs up or a little wink from them always brightened our day. We developed a unique bond with our patients and their relatives and would eagerly await news at handover of those whom we had taken care of during our previous shift. We sadly lost a few, but many got better.

Dealing with extremely sick and dying patients must be difficult when dealt with on a regular basis, and we now realise that entering ophthalmology had removed us physically and emotionally from this kind of exposure. Therefore, we were vulnerable. We previously saw ourselves as optimistic and resilient, but we questioned these characteristics after working in a COVID ICU. However, we believe we have gained positive lessons from this experience.

Facing countless challenges, including high personal risk, our ICU consultants fought the natural inclination to step away fearfully and instead chose to step up and lead by example. Despite their excessive workloads, they went above and beyond the call of duty to care for their patients whilst welcoming, supporting and even teaching us, which, in turn, made a big difference to both patients and colleagues. Their efforts have inspired us to do the same.

Returning to ophthalmology brought a sense of relief, though the experience of working in the ICU with COVID patients has changed us for the better. Of course the threat to our health, training, family and social lives continues, and we returned to a different eye clinic compared to the one we had left behind. The fleeting daily question that used to cross our minds of whether we were at increased risk due to our ethnic backgrounds seems to have ceased. Perhaps this question has stopped plaguing us because we no longer directly face the overt reminder of those most afflicted by this virus, or because of the realisation that so many of our colleagues in the NHS fall into the BAME categories. With the disproportionate impact of COVID on BAME communities, we continue to worry about our colleagues and our families, and wonder whether the normality we used to know will ever safely resume. We also think about the welfare and safety of the ICU team, many now our friends, continuing bravely to expose themselves to high viral loads while they strive for the absolute best for their vulnerable patients.

We all agree this experience has been one of the toughest and also one of the most rewarding of our lives. We feel honoured to have been 
chosen to make our own small contribution during this pandemic. The impact of this virus is likely to be long-lasting and widespread, and our thoughts are with our colleagues, patients and all those families who have been affected.

\section{Conflicts of Interest}

The authors declare they have no conflicts of interest.

\section{Author Affiliations}

1. Frimley Park Hospital NHS Foundation

Trust, Frimley, UK 